JURNAL ILMIAH KOMPUTERISASI AKUNTANSI, Vol. 14, No. 2,Desember 2021, pp. 230 - 239 p-ISSN : 1979-116X (print)

e-ISSN : 2614-8870 (online)

http://journal.stekom.ac.id/index.php/kompak

- page 230

\title{
Faktor-Faktor Yang Mempengaruhi Konsumen Menggunakan Jasa Pengiriman PT Pos Indonesia (Soreang)
}

\author{
Irma Widya Astuti ${ }^{1}$, Prihartono Aksan Halim ${ }^{2}$, Wahyu Trimastuti ${ }^{3}$ \\ ${ }^{1}$ Politeknik Piksi Ganesha /Fakultas Ekonomi dan Bisnis \\ J1. Gatot Subroto No. 301, e-mail: iwastuti@piksi.ac.id \\ ${ }^{2}$ Politeknik Piksi Ganesha /Fakultas Ekonomi dan Bisnis \\ Jl. Gatot Subroto No. 301, e-mail: prihartono@ piksi.ac.id \\ ${ }^{3}$ Politeknik Piksi Ganesha /Fakultas Ekonomi dan Bisnis \\ Jl. Gatot Subroto No. 301.
}

\section{ARTICLE INFO}

Article history:

Received 30 September 2021

Received in revised form 2 November 2021

Accepted 10 November 2021

Available online 1 Desember 2021
ABSTRACT

The research aimed to determine the effect of price, location, and service quality on the decision of use services of PT. Pos Indonesia, Soreang, Kabupaten Bandung. The population in this study was consumers who had used the services of PT Pos Indonesia, Soreang. The sampling collection technique used accident sampling with a total of 100 respondents. The data analysis technique used in this research is multiple linear regression. The result of multiple linear regression analysis shows that the variables of price, location and service quality simultaneously have a positive relation to consumer decision. Based on the results of the f test, it shows that the variables of price, location, and service quality simultaneously have a positive and significant impact on consumers decisions. The result of the coefficient of determination is 0.55 or $55 \%$, meaning that independent variables such as price, location, and service quality can explain variations in consumer decisions to choose the delivery service of PT Pos Indonesia (Soreang). While the remaining $45 \%$ of other variables not examined in this study. Company management should pay attention to parking spaces and price competitiveness to increase consumer interest in using the delivery service of PT Pos Indonesia (Soreang).

Keywords:Price, location, service quality, consumer decision. 


\section{Pendahuluan}

Di era modern sekarang ini, perubahan teknologi serta industri mempengaruhi aktivitas para pelaku bisnis. Laju dunia bisnis saat ini sangat kompetitif, mengakibatkan perusahaan-perusahaan di bidang barang maupun jasa mengalami banyak inovasi dan kreatifitas demi memenuhi kebutuhan konsumen. Saat ini masyarakat lebih cermat dalam menggunakan jasa atau produk yang akan mereka gunakan atau beli. Hal ini mendorong para pelaku bisnis untuk mempertahankan pasarnya dan meningkat jumlah pelanggan, terutama di bidang jasa pengiriman. Jasa pengiriman yang masyarakat butuhkan saat ini yaitu jasa pengiriman barang yang lebih cepat pengirimannya, efektif, efisien, aman dan barang sampai dengan selamat ke tujuan yang tepat. Perkembangan jasa pengiriman di Indonesia saat ini sangat tinggi, bersamaan dengan kebutuhan konsumen yang semakin bertambah dan semakin canggih teknologi yang ada, telah banyak penyedia jasa pengiriman sejenis yang memiliki tarif harga dan kualitas yang beragam, seperti Tiki, Pos Indonesia, JNE, SiCepat Ekspress, J\&T DHL, UPS, dan lain-lain.

Salah satu perusahaan yang ikut meramaikan layanan pengiriman di Indonesia yakni PT Pos Indonesia. Layanan Pos Indonesia yang terus mengalami perkembangan dalam meramaikan persaingan jasa logistik, sehingga bisa melayani pengiriman barang maupun uang sampai sekarang. Pos Indonesia yang telah menyediakan jasa pengiriman dari tahun 1946 hingga saat ini, banyaknya pesaing-pesaing swasta di bidang sejenis, jadi tantangan bagi PT Pos Indonesia yang awalnya sebagai pemimpin pasar monopoli, saat ini semakin tergerus oleh perkembangan jasa pengiriman swasta yang lebih unggul dalam melayani dan memuaskan kebutuhan konsumen saat ini. Hasil dari TBA (Top Brand Award) 2020 dimana indeks Pos Indonesia 7,7\%, JNE 27,3\%, , TIKI 10,8\%, J\&T 21,3\% dan DHL 4,1\% [1] . Menurut hasil Top Brand Award 2020 JNE menjadi jasa pengiriman populer dengan prosentase 27,3\% sedangkan PT Pos Indonesia berada di peringkat 4 dengan prosentase sebesar 7,7\% berdasarkan hasil Top Brand Award 2020, PT Pos Indonesia tertinggal jauh dengan perusahaan swasta yang mampu memenuhi kebutuhan dan keinginan konsumen.

Keberhasilan penyedia jasa pengiriman tidak terlepas dari keputusan konsumen. Banyak yang menjadi faktor pertimbangan bagi konsumen ketika akan memutuskan mengonsumsi suatu jasa atau produk yang dijual. Berbagai potongan harga atau diskon besar-besaran, dapat mendorong minat konsumen untuk mengonsumsi suatu jasa atau produk. Maka dari itu, dibutuhkan strategi penetapan tarif harga yang mampu memenuhi keinginan konsumen, namun tidak merugikan pendapatan perusahaan. Adapun lokasi bisnis yang mudah diakses atau mudah ditemukan keberadaannya, akan membuat para konsumen loyal terhadap jasa atau produk yang dijual, sehingga akan meningkatkan pembelian ulang terhadap produk yang dijual. Kualitas pelayanan menjadi salah satu pengaruh besar bagi kemajuan perusahaan, keunggulan kualitas layanan yang diperoleh konsumen, akan menjadi pertimbangan konsumen untuk kembali menggunakan atau membeli jasa atau produk yang kita jual.

Menurut Yospita, dkk (2020) dalam hasil penelitiannya menyimpulkan kepuasan konsumen dipengaruhi oleh kualitas pelayanan, harga dan lokasi [2]. Namun, dalam penelitian ini peneliti menggunakan keputusan konsumen sebagai variabel terikatnya.

JURNAL ILMIAH KOMPUTERISASI AKUNTANSI Vol. 14, No. 2, Desember 2021 : $230-239$ 
Seperti penelitian sebelumnya oleh Nurlina, dkk (2019) memaparkan keputusan kosumen dipengaruhi signifikan oleh harga, lokasi, dan kualitas pelayanan [3].

Berdasarkan pendahuluan yang telah diuraikan, peneliti bermaksud untuk menganalisis bagaimana faktor-faktor yang berpengaruh pada keputusan konsumen menggunakan jasa pengiriman PT Pos Indonesia cabang Soreang.

\section{Tinjauan Pustaka}

Harga yaitu sebuah nilai yang dibelanjakan agar dapat merasakan manfaat dari jasa atau barang yang dijual [4]. Adapun menurut Hardiansyah, dkk (2019) harga yakni unsur pemasaran yang mempengaruhi tingkat keuntungan perusahaan [5]. Tarif harga yang ditawarkan perusahaan akan diseleksi oleh konsumen lalu dibandingkan dengan tarif harga yang ditetapkan perusahaan lain. Dengan demikian harga merupakan elemen penting bagi perusahaan, artinya dibutuhkan strategi penetapan harga yang dapat menarik minat konsumen, seperti pemberian diskon atau potongan harga.

Lokasi merupakan tempat berlangsungnya berbagai kegiatan perusahaan untuk melayani kebutuhan konsumen akan suatu produk atau jasa [6]. Pemilihan lokasi usaha, sangat penting untuk meningkatkan pendapatan perusahaan, konsumen akan memilih jasa pengiriman dengan lokasi yang mudah ditemukan [7]. Selain itu, lahan parkir yang luas serta terjamin keamanannya menunjang keputusan konsumen.

Kualitas layanan menurut Barus dan Silalahi (2021) merupakan sebuah bentuk tindakan atau usaha yang dilakukan perusahaan dalam rangka mewujudkan harapan yang diinginkan konsumen [8]. Dengan memberikan kualitas pelayanan terbaik konsumen akan merasa puas sehingga mencegah beralihnya konsumen ke jasa pengiriman lain.

Menurut Kotler dan Amstrong (2012) keputusan konsumen merupakan tindakan konsumen menggunakan atau membeli jasa atau barang dengan mempertimbangkan alternatif yang ada guna memenuhi kebutuhan dan keinginannya [4]. Menurut Kotler dan Keller (2009) terdapat empat indikator keputusan konsumen yakni : 1) kemantapan atau keyakinan konsumen pada sebuah produk atau jasa, 2) kebiasaan menggunakan jasa atau produk tertentu, 3) pembelian kembali produk atai jasa, dan 4) menawarkan produk atau jasa pada kerabat dekat atau teman [9].

\subsection{Pengembangan Hipotesis}

\section{Keterkaitan Harga dengan Keputusan Konsumen}

Harga yakni sebuah nilai yang dibelanjakan agar dapat merasakan manfaat dari jasa atau barang yang dijual [4]. Dengan demikian, tarif harga yang ditetapkan perusahaan dapat mempengaruhi pola pemikiran konsumen. Seperti yang dikatakan oleh Kotler dan Amstrong (2012) terdapat empat indikator harga yakni jumlah yang dibelanjakan sesuai dengan kualitas yang diharapkan, harga yang terjangkau, kemampuan perusahaan dalam menetapkan tarif harga dibawah rata-rata pasar sehingga dapat bersaing dengan perusahaan lain, serta manfaat yang diperoleh sesuai dengan jumlah yang dikeluarkan [4]. Hardiansyah, dkk (2019) membuktikan harga berdampak signifikan pada keputusan konsumen [5].

H1 : Adanya pengaruh signifikan harga pada keputusan konsumen menggunakan jasa pengiriman PT Pos Indonesia cabang Soreang.

Faktor-Fakor Yang Mempengaruhi Konsumen Menggunakan Jasa PT Pos Indonesia (Sereong) (Irma Widya Astuti,) 


\section{Keterkaitan Lokasi dengan Keputusan Konsumen}

Yang menjadi salah satu pendorong agar konsumen membeli jasa atau produk yang dijual yakni kemudahan menjangkau suatu tempat. Artinya pemilihan lokasi memiliki dampak pada keputusan konsumen. Menurut Fure (2013) mengatakan terdapat empat faktor dalam penetuan lokasi perusahaan yakni fasilitas lahan parkir yang luas dan terjamin keamanannya, lokasi yang mudah ditemukan keberadaannya oleh konsumen, memiliki lingkungan yang aman dan nyaman bagi konsumen, lokasi yang dapat diakses oleh kendaraan umum maupun pribadi [10]. Penelitian yang dilakukan Nahya (2019) menyatakan lokasi berdampak pada keputusan pembelian [11].

H2: Adanya pengaruh signifikan lokasi pada keputusan konsumen menggunakan jasa pengiriman PT Pos Indonesia cabang Soreang.

\section{Keterkaitan Kualitas Pelayanan dengan Keputusan Konsumen}

Kualitas layanan merupakan keunggulan yang diberikan perusahaan dengan tujuan agar konsumen merasa puas. Keunggulan tersebut meliputi : 1) Empati, yaitu layanan yang diberikan oleh petugas dengan penuh perhatian dan pengertian, 2) Reliabilitas, yaitu kecermatan petugas dalam melayani, 3) Jaminan, kemampuan petugas dalam memberikan jaminan kepercayaan atas pelayanan yang diberikan. Contohnya seperti jaminan dalam melayani konsumen dengan tepat waktu, 4) Responsivitas, yaitu ketanggapan petugas dalam membantu dan melayani kebutuhan dan keinginan konsumen dengan cepat, 5) Bukti fisik, yaitu bentuk pelayanan yang diberikan oleh perusahaan berupa bentuk konkret seperti kenyamanan ruangan, penampilan petugas yang rapih, dan kelengkapan peralatan kantor [6]. Keunggulan yang perusahaan berikan akan dipertimbangkan oleh konsumen, jika dirasa sesuai dengan ekspetasi, maka konsumen akan membeli atau menggunakan lagi jasa yang dijual. Suhardi (2020) menyimpulkan adanya dampak signifikan kualitas pelayanan pada keputusan pembelian[12].

H3: Adanya pengaruh signifikan kualitas pelayanan pada keputusan konsumen menggunakan jasa pengiriman PT Pos Indonesia cabang Soreang

\subsection{Kerangka Berpikir}

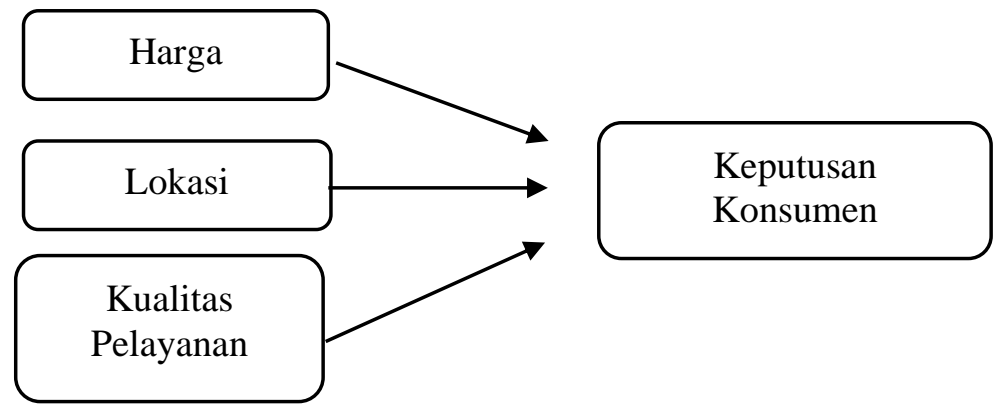

Gambar 1 Kerangka Konseptual Sumber : Data diolah, 2021

\section{Metode Penelitian}

JURNAL ILMIAH KOMPUTERISASI AKUNTANSI Vol. 14, No. 2, Desember 2021 : $230-239$ 
Metode yang dipakai dalam penelitian ini yakni pendekatan kuantitatif. Menurut Creswell (2012) pendekatan kuantitatif merupakan penelitian yang dilakukan untuk mengetahui pengaruh suatu variabel pada variabel lain [13].

Seluruh pengguna jasa pengiriman Pos Soreang menjadi populasi dalam penelitian ini. Teknik accident sampling yang dipilih peneliti dalam pengambilan sampel, yaitu siapa saja pengguna jasa pengiriman Pos Soreang yang secara tidak sengaja berjumpa dengan peneliti dan dirasa cocok dijadikan sampel penelitian [14].

Data primer yakni informasi yang didapatkan melalui kuisioner online yang disebar pada konsumen yang pernah menggunakan jasa pengiriman Pos Soreang lebih dari 2 kali. Dalam menentukan banyaknya sampel, peneliti menggunakan rumus unknown population. Lalu didapatkan hasil berikut ini :

$$
\begin{aligned}
n & =\frac{Z}{4 \mu^{2}} \\
n & =\frac{1,96^{2}}{4(0,1)^{2}} \\
n & =96,04
\end{aligned}
$$

Menurut hasil perolehan dengan rumus unknown population diperlukan sampel sebanyak 96,4 responden, guna mendapatkan hasil yang benar-benar representatif, lalu sebanyak 100 responden diambil peneliti untuk dijadikan sampel. Metode analisis yang digunakan yakni regresi linier berganda, sebelum itu dilakukan uji asumsi klasik untuk mengetahui konsisten tidaknya persamaan regresi.

Model uji untuk hipotesis yang digunakan yakni uji secara parsial dan uji secara simultan. Uji $\mathrm{T}$ dilakukan untuk mengetahui pengaruh masing-masing variabel $\mathrm{X}$ pada variabel $\mathrm{Y}$. Sedangkan, uji $\mathrm{F}$ dilakukan utuk mengatahui pengaruh variabel $\mathrm{X}$ secara bersamaan pada variabel $Y$.

\section{HASIL DAN PEMBAHASAN}

\subsection{Uji Asumsi Klasik}

\section{Uji Normalitas}

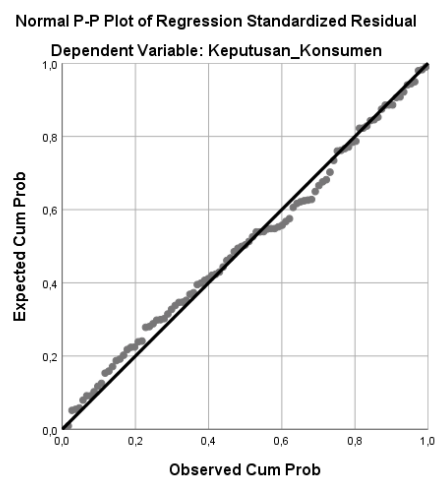

Gambar 2 Uji Normalitas

Sumber : Data diolah, 2021

Faktor-Fakor Yang Mempengaruhi Konsumen Menggunakan Jasa PT Pos Indonesia (Sereong) 
Titik-titik pada gambar 2 menyebar mendekati garis diagonal, dapat disimpulkan perdistribusian data pada penelitian ini normal.

\section{Uji Multikolinieritas}

Tabel 2 Uji

\begin{tabular}{|l|l|l|c|}
\hline \multirow{2}{*}{ Model Collinearity Statistics } & \multicolumn{2}{|c|}{ Tolerance } & VIF \\
\cline { 2 - 4 } \multicolumn{1}{c}{} & HARGA(X1) & 776 & 1,288 \\
\hline LOKASI(X2) & 767 & 1,304 \\
\hline KUALITAS &, 744 & 1,344 \\
PELAYANAN(X3) & & \\
\hline
\end{tabular}

Multikolinieritas

Sumber : Data diolah, 2021

Besaran Tolerance dari harga, lokasi, serta kualitas pelayanan $<0,10$ berarti variabel bebas dalam penelitian terbebas dari multikolinieritas. Begitupun besaran VIF kurang dari $10 \%$. Lalu diartikan variabel bebas dalam penelitian tidak ada multikolinieritas.

\section{Uji Heteroskedastisitas}

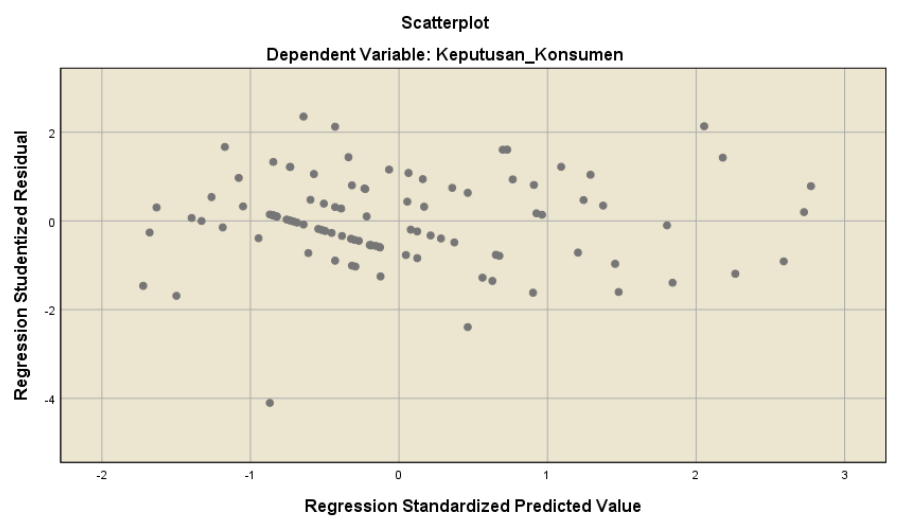

Gambar 3 Uji Heteroskedastisitas

Sumber : Data diolah, 2021

Titik-titik pada gambar 3 yang menyebar secara tidak beraturan mengidentifikasi bahwa tidak terjadi masalah heteroskedastisitas.

\subsection{Analisis Data dan Uji Hipotesis}

\subsubsection{Analisis regresi linier berganda}

JURNAL ILMIAH KOMPUTERISASI AKUNTANSI Vol. 14, No. 2, Desember 2021 : $230-239$ 
Tabel 3 Hasil Analisis Regresi Linier Berganda

Sumber : Data diolah, 2021

Menurut hasil tabel di atas maka didapatkan hasil persamaan regresi bergandanya yaitu sebagai berikut :

$\mathrm{Y}=2,335+0,192 \mathrm{X}_{1}+0,43 \mathrm{X}_{2}+0,696 \mathrm{X}_{3}+\mathrm{e}$

1) Konstanta dengan besar 4,993, diartikan pengaruh variabel bebas $=0$, lalu keputusan konsumen menggunakan jasa pengiriman Pos Soreang yaitu sebesar 2,335 satuan.

2) Besaran regresi harga 0,192 dan bernilai positif maka jika harga bertambah 1 satuan, keputusan konsumen menggunakan jasa pengiriman Pos Soreang juga bertambah sebesar 0,192 satuan.

3) Besaran regresi lokasi 0,43 dan bernilai positif maka jika lokasi bertambah 1 satuan, keputusan konsumen menggunakan jasa pengiriman Pos Soreang juga bertambah sebesar 0,43 satuan.

4) Besaran regresi kualitas pelayanan 0,696 dan bernilai positif maka kualitas pelayanan bertambah 1 satuan, keputusan konsumen menggunakan jasa pengiriman Pos Soreang juga bertambah sebesar 0,696 satuan.

5) Berdasarkan hasil analisis regresi berganda, koefisien kualitas pelayanan mempunyai pengaruh lebih besar dibandingkan dengan koefisien regresi lain yang ada dalam penelitian ini, dengan besaran nilai regresi 0,696.

\subsubsection{Pengujian Hipotesis}

\section{Uji Hipotesis Model Parsial}

Setelah dilihat dari hasil tabel 3 di atas, ternyata tidak semua variabel bebas memilki pengaruh signifikan terhadap variabel terikatnya. Nilai variabel harga dengan signifikasi $0,14>0,05$ dan $t_{\text {hitung }} 2,512>t_{\text {tabel }} 1,664$ berarti adanya pengaruh positif tetapi tidak signifikan pada keputusan konsumen menggunakan jasa pengiriman Pos Soreang, dengan demikian $\mathrm{H} 1$ ditolak.

Hasil pengujian hipotesis variabel lokasi menunjukkan bahwa $\mathrm{H} 2$ ditolak dan variabel lokasi tidak berpengaruh signifikan pada keputusan konsumen menggunakan jasa pengiriman Pos Soreang. Hal ini ditunjukkan oleh hasil $t_{\text {hitung }} 0,441<t_{\text {tabel }} 1,664$ dan

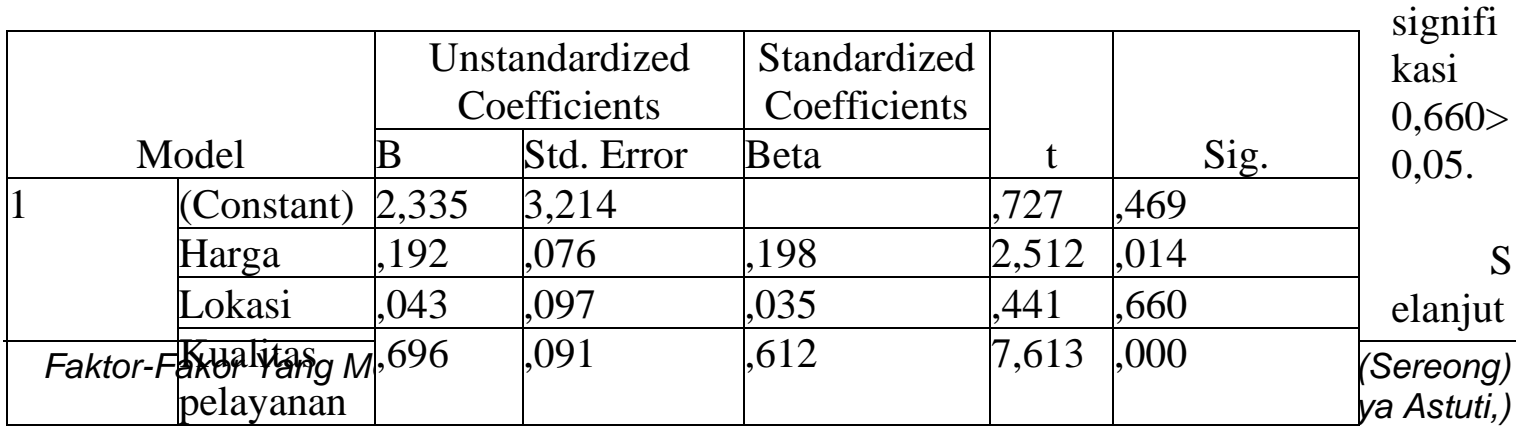


nya hasil uji hipotesis variabel kualitas layanan dengan besaran signifikasi $0,000<0,05$ serta $t_{\text {hitung }} 7,613>t_{\text {tabel }}$ 1,664 menunjukkan bahwa $\mathrm{H} 3$ diterima berarti keputusan konsumen menggunakan jasa pengiriman Pos Soreang dipengaruhi signifikan oleh kualitas layanan dengan nilai positif.

\section{Uji Hipotesis Model Simultan}

Tabel 4 Hasil Uji Anova

\begin{tabular}{|c|c|c|c|c|c|c|}
\hline \multicolumn{2}{|c|}{} & Sum of Squares & Df & Mean Square & F & Sig. \\
\hline \multirow{3}{*}{1} & Regression & 57,875 & 3 & 19,292 & 16,582 &, $000^{\mathrm{b}}$ \\
\cline { 2 - 7 } & Residual & 111,685 & 96 & 1,163 & & \\
\cline { 2 - 7 } & Total & 169,560 & 99 & & & \\
\hline
\end{tabular}

Sumber : Data diolah, 2021

Menurut hasil uji hipotesis simultan tabel di atas, diketahui bahwa besarnya $F_{h i t u n g}$ $16,58>F_{\text {tabel }} 2,70$, artinya variabel keputusan konsumen menggunakan jasa pengiriman Pos Soreang secara bersamaan dipengaruhi signifikan oleh harga, lokasi, juga kualitas pelayanan. Seperti hasil penelitian sebelumnya yang diteliti oleh Purbowati (2018) dan Perdana (2019) bahwa keputusan konsumen menggunakan jasa pengiriman dipengaruhi signifikan secara bersamaan oleh harga, lokasi, dan kualitas pelayanan[15], [16].

\section{Koefisien Determinaasi}

Tabel 5 Koefisien Determinasi $\left(\mathrm{R}^{2}\right)$

\begin{tabular}{|c|c|c|c|c|}
\hline Model & R & R Square & Adjusted R Square & Std. Error of the Estimate \\
\hline 1 &, $741^{\mathrm{a}}$ &, 550 &, 535 & 1,64584 \\
\hline
\end{tabular}

Sumber : data diolah, 2021

Menurut tabel 5 dapat dipaparkan nilai (R Square) yaitu 0,55, diartikan bahwa sebesar 55\% variabel bebas dalam penelitian ini, memiliki pengaruh pada keputusan konsumen menggunakan jasa pengiriman Pos Soreang, kemudian sebesar 0,45 atau 45\% sisanya disebabkan variabel lain yang tidak diuji oleh peneliti.

\subsection{Pembahasan}

\section{Keterkaitan harga dengan keputusan konsumen}

Hasil penelitian Perdana (2019) menyatakan keputusan konsumen dipengaruhi signifikan oleh harga dengan nilai positif [15]. Dengan demikian hasil penelitian ini terdapat perbedaan, dimana dalam penelitian ini harga tidak signifikan pada keputusan konsumen menggunakan jasa pengiriman Pos Soreang. Penetapan harga tarif jasa pengiriman Pos Soreang yang tepat, akan menarik perhatian dari konsumen untuk menggunakan kembali jasa pengiriman Pos Soreang. Pada umumnya konsumen menyukai harga suatu jasa atau barang sebanding dengan harapan dan manfaat yang diperoleh, dengan begitu konsumen tidak akan ragu menggunakan jasa pengiriman Pos Soreang. Kemudian pemberian diskon atau potongan harga juga akan berdampak pada pertimbangan konsumen untuk menggunakan jasa yang dijual.

\section{Keterkaitan lokasi dengan keputusan konsumen}

JURNAL ILMIAH KOMPUTERISASI AKUNTANSI Vol. 14, No. 2, Desember 2021 : $230-239$ 
Hasil penelitian Purbowati (2018) yang menunjukkan bahwa variabel keputusan konsumen dipengaruhi signifikan oleh lokasi dengan nilai positif [16]. Adapun hasil penelitian dari Hardiansyah dkk, (2019) yang searah dengan penelitian ini, yang menyimpulkan lokasi tidak mempengaruhi keputusan konsumen [5]. Lokasi Pos Soreang berada ditempat yang strategis, namun lahan parkir yang sempit menjadi keluhan para konsumen pengguna jasa Pos Soreang. Dengan demikian perlunya perhatian dari manajemen perusahaan untuk memperbaiki atau mengatur kembali tata lahan parkir agar para konsumen tidak berpindah ke jasa pengiriman lain. Juga akan memberikan rasa nyaman dan aman pada konsumen. Yang akan berdampak pada pertimbangan konsumen untuk menggunakan jasa pengiriman Pos Soreang.

\section{Keterkaitan kualitas pelayanan dengan keputusan konsumen}

Hasil yang didapat dalam penelitian ini yaitu adanya dampak signifikan kualitas pelayanan pada keputusan konsumen. Seperti penelitian sebelumnya dari Nurlina dkk, (2019) membuktikan keputusan konsumen dipengaruhi secara signifikan oleh kualitas pelayanan dengan nilai positif [3]. Menurut Barus dan Silalahi (2021) kualitas layanan merupakan sebuah bentuk tindakan atau usaha yang dilakukan perusahaan dalam rangka mewujudkan harapan yang diinginkan konsumen [8]. Pos Soreang senantiasa melayani dengan cepat tanggap, sopan dan penuh penuh perhatian. Hal ini membuat konsumen merasa bahwa keunggulan yang diberikan Pos Soreang mampu memenuhi harapan konsumen. Dengan demikian, untuk kedepannya Pos Soreang sebaiknya terus meningkatkan keunggulan kualitas layanannya, agar mencegah berpindahnya konsumen ke jasa pengiriman lain.

\section{Kesimpulan dan Saran \\ 5.1 Kesimpulan}

1. Dari hasil uji hipotesis masing-masing menunjukkan bahwa : a) harga memiliki pengaruh positif namun tidak signifikan pada keputusan konsumen menggunakan jasa pengiriman Pos Soreang, b) kualitas pelayanan memiliki pengaruh positif dan signifikan pada keputusan konsumen menggunakan jasa pengiriman Pos Soreang, dan 3) lokasi tidak memiliki pengaruh positif dan tidak signifikan pada keputusan konsumen menggunakan jasa pengiriman Pos Soreang.

2. Hasil uji hipotesis secara simultan menunjukkan bahwa keputusan konsumen dalam menggunakan jasa pengiriman Pos Soreang secara bersamaan dipengaruhi signifikan oleh variabel harga, lokasi, dan kualitas pelayanan.

3. Hasil pengujian koefisien determinasi yaitu 0,55 artinya variabel bebas seperti harga, lokasi, dan kualitas layanan dapat menjelaskan variasi keputusan konsumen menggunakan jasa pengiriman Pos Soreang. Kemudian sebesar 0,45 atau 45\% sisanya disebabkan variabel lain yang tidak diuji oleh peneliti

\subsection{Saran}

1. Sebaiknya Pos Soreang memperhatikan lahan parkir dan keamanannya agar dapat meningkatkan keinginan konsumen untuk menggunakan jasa pengiriman Pos Soreang.

2. Pos Soreang sebaiknya memperhatikan daya saing harga dengan pesaing lain. Misalnya seperti menggunakan strategi diskon, bagi konsumen yang 
menggunakan layanan pengiriman Pos Soreang akan mendapatkan diskon dengan syarat dan kebijakan tertentu. Hal ini dapat mendorong konsumen menggunakan jasa pengiriman Pos Soreang.

3. Pos Soreang sebaiknya mempertahankan dan meningkatkan kualitas pelayanan yang diberikan karena menurut hasil penelitian, pengaruh paling besar dari variabel bebas yang memiliki pengaruh besar dalam menggunakan jasa Pos Soreang yaitu kualitas pelayanan.

4. Bagi penelitian selanjutnya disarankan menggunakan variabel bebas yang tidak terdapat pada penelitian ini.

\section{Reference}

[1] T. B. Award, "Jasa Kurir Fase 2 2020," 2020. https://www.topbrandaward.com/en/2020/06/jasa-kurir-fase-2-2020/.

[2] B. Y. Yospita, R. V. Sinaga, and Sagala Roslinda, "Pengaruh Kualitas Pelayanan, Harga dan Lokasi Terhadap Kepuasan Konsumen (Studi Kasus Pada Milala Service Station Medan)," Jurnal Manajemen dan Bisnis, vol. 20, pp. 141-150, 2020.

[3] Nurlina, Milasari, and D. R. Indah, "Pengaruh Kualitas Pelayanan , Harga dan Lokasi terhadap Keputusan Penggunaan Jasa Pengiriman Barang PT . Citra Van Titipan Kilat Kota Langsa," Jurnal Samudra Ekonomika., vol. 3, no. 1, pp. 1-8, 2019.

[4] Kotler and Amstrong, Prinsip-Prinsip Pemasaran, 13th ed. Jakarta: Erlangga, 2012.

[5] F. Hardiansyah, M. Nuhung, and I. Rasulong, "Pengaruh Lokasi dan Harga Terhadap Keputusan Pembelian Pada Restoran Singapore di Makassar," Jurnal Ilmu Manajemen Profitability., vol. 3, no. 1, pp. 90-107, 2019.

[6] Tjiptono, Pemasaran Jasa-Prinsip, Penerapan, dan Penelitian. Yogyakarta: Andi Offset, 2014.

[7] B. Alma, Manajemen Pemasaran dan Pemasaran Jasa Cetakan Kesepuluh. Bandung: Alfabeta, 2013.

[8] C. S. Barus and D. Silalahi, "Pengaruh Promosi Media Sosial Dan Kualitas Pelayanan Terhadap Keputusan Pembelian Konsumen Pada Sosmed Cafe Abdullah Lubis Medan," Jurnal Manajemen dan Bisnis, vol. 21, pp. 1-15, 2021.

[9] Kotler and Keller, Manajemen Pemasaran, 13th ed. Jakarta: Erlangga, 2009.

[10] H. Fure, "Lokasi, Keberagaman Produk, Harga, dan Kualitas Pelayanan Pengaruhnya Terhadap Minat Beli Pada Pasar Tradisional Bersehati Calaca," EMBA, vol. 1, no. 3, pp. 273-283, 2013.

[11] S. Nahya, "Pengaruh Harga, Kualitas Produk, dan Lokasi Terhadap Keputusan Pembelian (Studi Kasus Pada Kosumen DRK Cafe Bondowoso)," J. Ilm. Ris. Manaj., vol. 8, no. 11, pp. 150-165, 2019.

[12] Y. Suhardi, A. Syachroni, A. Burda, and A. Darmawan, "Pengaruh Keragaman Produk , Persepsi Harga , Dan Kualitas Pelayanan Terhadap Keputusan Pembelian Konsumen,” J. STEI Ekon., vol. 29, no. 02, pp. 17-30, 2020.

[13] J. W. Creswell, Research Design Pendekatan Kualitataif, Kuantitatif, dan Mixed. Yogyakarta: Pustaka Pelajar, 2012.

[14] Sugiyono, Metode Penelitian Kombinasi (Mix Methods). Bandung: Alfabeta, 2015.

JURNAL ILMIAH KOMPUTERISASI AKUNTANSI Vol. 14, No. 2, Desember 2021 : $230-239$ 
[15] F. I. Perdana, "Pengaruh Kualitas Pelayanan , Harga , dan Lokasi Terhadap Keputusan Penggunaan Jasa PT . Pos Indonesia Surabaya," J. Ilmu dan Ris. Manaj., vol. 8, no. 7, pp. 1-18, 2019.

[16] D. Purbowati, "Faktor-Faktor yang Mempengaruhi Konsumen Memilih Jasa Pengiriman PT. Pos Indonesia di Kota Samarinda," J. Adm. Bisnis FISIPOL UNMUL, vol. 6, no. 3, pp. 869-880, 2018. 